\title{
O FANTASMA DA MERCADORIA: UMA LEITURA MATERIALISTA DO FLÂNEUR BENJAMINIANO
}

Rosana Biondillo

\begin{abstract}
RESUMO
O intuito é apresentar o flâneur benjaminiano como sujeito histórico com feições materialistas e não apenas como uma metáfora menor do poeta boêmio e despolitizado. Optamos por nos aproximar do tema tendo como pano de fundo a troca de correspondência Benjamin - Adorno no que tange especificamente à temática do flâneur, bem como o poema "Os setes velhos" de Baudelaire - que Benjamin concebeu como final para o flâneur como apresentado no "Exposé de 1939".
\end{abstract}

Palavras-chave: Flâneur. Erfahrung. Chockerlebnis. Fantasmagoria. Modernidade.

\section{THE PHANTOM OF COMMODITY: A MATERIALISTIC READING OF THE BENJAMINIAN FLÂNEUR}

\begin{abstract}
The intention is to present the benjaminian flâneur as a historical individual with materialistic features and not only as a minor metaphor of the bohemian and polytically alienated poet. We have chosen to attain to the subject in accordance with the Benjamin - Adorno's correspondence exchange, specifically on the flâneur theme, as well as to Baudelaire's poem "The seven old men", which Benjamin sellected to match with his planned final interpretation of the flâneur specially as described on the "Exposé of 1939".
\end{abstract}

Key words: Flâneur. Erfahrung. Chockerlebnis. Phantasmagoria. Modernity.

Quando Benjamin escreve o ensaio Paris do Segundo Império em 1938 - que é composto por três capítulos: "A boêmia", "O flâneur", "A modernidade" - e o apresenta ao Instituto de Pesquisas Sociais para avaliação e publicação, recebe as críticas e sugestões de Adorno em carta datada de 10 de novembro desse mesmo 
ano. ${ }^{1}$ Dessa correspondência nasce uma polêmica que se tornou conhecida no tocante à nossa temática: o flâneur. ${ }^{2}$ Em linhas gerais, a crítica de Adorno a Benjamin recai sobre a abstenção de mediação no tratamento do conceito marxiano de fantasmagoria e do fetichismo da mercadoria. No contexto específico do flâneur, Adorno chama a atenção para o fato das passagens (galerias de Paris) ${ }^{3}$ serem introduzidas "como uma referência à estreiteza dos trottois, que impediria o avanço do flâneur nas ruas," (ADORNO, 2012, 400) incluindo ainda a polêmica do imposto sobre o vinho e também as barricadas, "que me parece particularmente problemático, porque é justo aqui que permanece precária a transição de uma elementar consideração teórica [...] para a representação 'concreta' do flâneur" (ADORNO, 2012, 402). Benjamin responde em 09 de dezembro de 1938, apoiandose em alusão de Adorno a uma tensão frutífera entre a "teoria do consumo do valor de troca", preconizada pelo próprio Adorno, e a sua teoria "da empatia com a alma da mercadoria" (ADORNO, 2012, 412). Diz Benjamin:

Também eu julgo aqui que se trata de uma teoria no sentido mais estrito da palavra, e a digressão sobre o flâneur nela culmina. Esse é o lugar, e com certeza o único nessa parte, no qual a teoria sobrevém com sua iniludível razão. Ela irrompe como um raio isolado numa câmara artificialmente escurecida. [...]. Daí por que essa teoria do flâneur [...] resgata na essência o que há muitos anos tenho em mente como uma representação do flâneur. (ADORNO, 2012, 412)

De fato, nossa menção a esse episódio tem como objetivo sucintamente colocar que, na concepção marxista de Adorno, essa teorização deveria se manifestar já no modo de produção das mercadorias, no interior das fábricas e no trabalho operário alienado que demanda mediação social, mas para Benjamin essa manifestação dá-se mormente na sua circulação e consumo, provocando identificação e movimento não-aderentes à lógica dessa mesma mediação. Desse modo, Benjamin corporifica a questão da cultura coisificada e já apresenta a mercadoria envolta na sedução proporcionada por um objeto de desejo que, embora inorgânico, suscita fantasias no consumidor e expressa o sex-appeal do inorgânico -

\footnotetext{
${ }^{1}$ Adorno, TW. Correspondência 1928-1940 Adorno - Benjamin, p. 398-410

${ }^{2}$ Nas pesquisas de Benjamin, o flâneur é um tipo social urbano que surge por volta de 1830 em Paris.

${ }^{3} \mathrm{O}$ termo Passagem refere-se especificamente às galerias de Paris. Todas as Passagens são, portanto, parisienses.
} 
concepção que revela que a reificação é a do próprio consumidor (e mesmo do trabalhador, que se torna cliente especialmente a partir do advento das Exposições Universais $^{4}$ ) -, enquanto que a mercadoria ganha uma espécie de "alma".

As mercadorias são os objetos-fetiche do capitalismo. Para Benjamin, o fetiche já é o artificial, o inorgânico que prescinde de mediação. O objeto, como mercadoria, penetra 0 âmago do sujeito numa simbiose praticamente inquebrantável: o sujeito coisifica-se enquanto que a mercadoria se animiza, se humaniza. Esse sujeito, de acordo com a teoria benjaminiana em questão, seria representado pelo flâneur - daí o flâneur como "alma" da mercadoria. A opção de Benjamin pela não-mediação conteria o potencial para confrontar a mediação realizada por uma racionalidade igualmente imersa na reificação. Sua proposta é ampla e reúne, além de Marx, também Freud. Nessa abordagem conjunta seria possível reencontrar "a dimensão política do fetiche", ao mesmo tempo em que é necessário demarcar as devidas restrições em ambos, como explica Olgária Matos:

Em Freud - que o identificava ao 'animismo regressivo' de caráter colonial e em Marx - que o circunscreve no âmbito do trabalho alienado devendo desaparecer em um mundo sem exploração e sem necessidade de ilusões (religiosas). Considerando o fetichismo em um plano autônomo com respeito às mercadorias, Benjamin indica a maneira pela qual ele existe nas tensões entre a religião e a constituição da vida social e afetiva. ${ }^{5}$ (MATOS, 2010, 273)

Apesar das diferenças e das tentativas de Benjamin em explicar (ao menos parcialmente) sua concepção com respeito às críticas feitas por Adorno, o que precisamos considerar é a categoria do desejo que envolve a mercadoria, por isso a expressão: sex-appeal do inorgânico. Pois o orgânico é o reino da primeira natureza, portanto da necessidade, enquanto que a mercadoria se relaciona com o inorgânico

\footnotetext{
${ }^{4}$ A primeira Exposição Universal (de caráter internacional e mundial) foi realizada em Londres em 1851 com a construção do Palácio de Cristal. Benjamin se refere à segunda, realizada em 1855 em Paris, como o marco que transformaria a Cidade Luz na capital do capital. Megaeventos de exaltação aos avanços técnicos e de ascensão da burguesia, as Exposições Universiais tornaram-se templos do capitalismo e do fetichismo das mercadorias, trouxeram à luz a dialética valor de exposição versus valor de troca e foram, segundo Benjamin, "as escolas onde as massas, apartadas do consumo, prenderam a empatia com o valor de troca". (ADORNO, 2012, p. 421)

${ }^{5}$ Matos, OCF. "Fetichismo e luxo: valor de exposição e imagens de desejo". In: Benjaminianas: cultura capitalista e fetichismo contemporâneo, 273. (Benjamin configura uma questão que extrapola - círculo apenas do consumo [fetichista] de mercadorias e nos insere em questionamentos biopolíticos mais amplos de uma sociedade tecnológica que propicia os meios para a inorganicidade sem precedentes.
} 
e pertence à segunda natureza. Enquanto que a primeira já está dada desde a origem e tem por finalidade suprir e satisfazer a realidade funcional e de subsistência definidamente orgânica das condições humanas, a segunda é fruto do desejo e representa uma satisfação que, embora valorizada, é aparente. A humanização da mercadoria, assim como sua auratização, é bem definida por Rouanet:

Os objetos-fetiche do capitalismo: as mercadorias. São elas que, autonomizadas, determinam o destino do homem. [...] A mercadoria-fetiche quer assumir um rosto humano. Reino do inorgânico, quer ser vista como orgânica. Quer ter uma casa, como os homens: as Passagens, onde ela é exibida... (ROUANET, 1990, 28-29)

Para que o flâneur pudesse ser observado como o "rosto humano" ou a "alma" da mercadoria, Benjamin procura levar em consideração as mencionadas críticas de Adorno e então escreve, a partir do capítulo "O flâneur", de Paris do Segundo Império, o ensaio Sobre alguns temas em Baudelaire publicado em 1939. Nesse novo ensaio, ele aborda o flâneur primordialmente relacionado ao conceito de vivência do choque (Chockerlebnis), pois: "o mundo moderno se caracteriza pela intensificação, levada ao paroxismo, das situações de choque, em todos os domínios" (ROUANET, 1990, 45). Com o flâneur, relaciona choque e jogo no confronto com a multidão e em estreita relação com o automatismo do trabalho operário nas linhas de montagem das fábricas. Para Benjamin: "A vivência do choque, sentida pelo transeunte na multidão, corresponde à 'vivência' do operário com a máquina" (BENJAMIN, 1994, 120). E embora o flâneur não seja um jogador no sentido estrito do termo, também vivia do jogo, era regido pelo mesmo princípio do prazer, era ocioso. Seu “jogo" é com a multidão.

Adiantamo-nos em relação ao paradoxo dessa comparação como pontuado por Benjamin ao analisar o fato de que Baudelaire ficara fascinado: "por um processo em que o mecanismo reflexo e acionado no operário pela máquina pode ser examinado mais de perto no indivíduo ocioso, como em um espelho. Esse processo é representado pelos jogos de azar" (BENJAMIN, 1994, 127). E se nada poderia ser mais antagônico do que comparar um trabalhador a um indivíduo ocioso e dado ao jogo, o conceito de vivência do choque os une, uma vez que ambas as condições, jogo e trabalho operário, são automatismos que levam ao esvaziamento 
e à impossibilidade de conquista de qualquer experiência prolongada: são automáticos no mau sentido e viciantes. No jogo, cada partida é independente de condições anteriores ou posteriores e não existe a dependência do passado. Se, em épocas precedentes, o trabalho - especialmente o artesanal, o intelectual e o artístico - era valorizado em seu aspecto de construção e transmissão de uma dada tradição, onde a prática levava à perfeição, no século XIX do flâneur torna-se repetição incessante e inconclusiva, adestramento que não leva a qualquer valoração, mas que demanda sobretudo um preço. Num dado sentido, torna-se evidente o conceito marxista de alienação - uma vez que se concretiza a cisão entre concepção e execução e o operário fica sujeito ao ritmo da linha de montagem e não detém o controle sobre seu ritmo normal de trabalho. Mas o que Benjamin quer demonstrar é a relação expressiva, ou a expressão dessa condição automática na sociedade, e não assumi-la como causa, como o fizera Marx - uma vez que esta não é apenas uma condição do trabalho dos operários nas fábricas, pois está igualmente presente no comportamento do jogador, que não tem nada de trabalhador e, muito menos, pertence a qualquer classe trabalhadora. $O$ que ele privilegia é a vivência do choque, a que estão expostos tanto o operário quanto o jogador. Por isso: "O arranque está para a máquina como o lance para o jogo de azar" (BENJAMIN, 1994, 127). O choque é a infraestrutura do capitalismo.

Georg Otte analisa a ligação trabalhador-jogador evidenciando a teoria das correspondências de Baudelaire nas elaborações de Benjamin. Diz-nos Otte: "Os choques aos quais essas duas figuras são expostas e que lhes impõem um comportamento 'reflexo' se refletem ao mesmo tempo através de 'correspondências' mútuas"6 (OTTE, 2007, 236). Portanto, se Baudelaire não tinha como explicitar essa noção entre jogo e trabalho operário de forma conceitual, Benjamin constata que ele mostrou como isso é possível mediante a seguinte analogia:

\footnotetext{
${ }^{6}$ E Otte completa: "Pensar por "correspondências" exige como primeira medida que o fluxo do pensamento linear seja interrompido por "choques", pois são estes que, por mais destrutivos que sejam, fazem com que elementos anteriormente distantes se aproximem e possam ser cotejados como correspondentes. $\mathrm{O}$ conhecimento proporcionado por esse procedimento pode não atender às exigências de um desenvolvimento teórico, encontrando assim a resistência da academia, mas, pelo menos em alguns casos, convence até seus próprios representantes. O próprio Adorno se mostrou especialmente impressionado pela passagem sobre o jogador e suas correspondências com o operário de fábrica. (OTTE, 2007, p. 237)
}

Mestre em Filosofia pela Unifesp. Residente em São Paulo - SP. Email: rosanabiondillo@gmail.com 
Cada operação com a máquina não tem qualquer relação com a precedente, da mesma forma que um lance na partida do jogo de seu precedente imediato, a jornada do operário assalariado representa, a seu modo, um correspondente à féria do jogador. Ambas as ocupações estão igualmente isentas de conteúdo. (BENJAMIN, 1994, 127)

A ideia do recomeçar sempre e mais uma vez é o que regula tanto o jogo quanto o trabalho operário. Por conseguinte, o que Benjamin quer validar é a questão da degeneração da experiência que, nessas condições, não pode dar-se, pois "o jogo invalida a ordem da experiência" (BENJAMIN, 1994, 129). Como expressão da vivência do choque, o jogo passa a ser o modo regulativo do tempo das classes burguesa e operária - da modernidade em geral - em que uma vez só é sempre pouco e sempre nada. E será sempre nada, pois o desejo não é projetado no distante que aperfeiçoa a experiência, mas na compulsão do imediato que a destrói: "Recorda: O Tempo é sempre um jogador atento / Que ganha, sem furtar, cada jogada! É a lei! //" (BAUDELAIRE, 2012, 301). O ponteiro dos segundos do relógio torna-se o "coadjuvante do jogador" (BENJAMIN, 1994, 130) e marca o tempo da repetição e da inconclusão, onde não existe espaço para a recordação. "O tempo", diz Benjamin, "é o tecido no qual as fantasmagorias do jogo são urdidas" (BENJAMIN, 1994, 130).

Com as alterações que Benjamin realizou, tendo em vista as observações de Adorno, surgem algumas considerações que julgamos necessário salientar, pois produzem duas versões do flâneur. Contudo, com essa atitude comparativa, a intenção não é dividir as concepções de flâneur benjaminiano, mas apontar seu tratamento nesses definidos momentos e salientar que os consideramos ainda mais representativos da sua importância dentro do contexto geral das Passagens. Portanto, quando nos referimos a duas versões do flâneur, o fazemos no seguinte sentido: se avaliarmos o tratamento dado por Benjamin ao flâneur no primeiro ensaio, Paris do Segundo Império, veremos que há uma aproximação positiva deste com a multidão com vistas a uma interação com o conceito de fantasmagoria e com a alma da mercadoria, pois o ensaio tem três partes que se complementam para traçar essa relação e o flâneur ainda mantém traços de autonomia, pois configura-se a possibilidade de interação com uma multidão capaz de propiciar choques estimulantes, que se traduzem em uma descarga de energia revigorante para o 
flâneur - mesmo que funcione também como uma compensação para o tédio. Essa multidão é constituída de tipos literários e políticos com os quais o flâneur interage e que ajudariam a formar um retrato ainda sugestivo e um tanto menos angustiante do herói moderno. Já no ensaio Sobre alguns temas em Baudelaire, o tratamento do flâneur em sua relação com a multidão dá-se mediante vivência do choque e jogo na esfera do princípio de depreciação da autonomia. Vemos também que no final quando Benjamin analisa o poema em prosa "Perda de auréola" -, o flâneur não é mais flâneur, pois volta-se com sua esgrima contra a massa e transforma-se no tipo trágico(-patético) que resta ao pretenso herói moderno representar. Há também a prevalência das análises sociológicas de Simmel no primeiro ensaio e ênfase às de Freud no segundo, especialmente no tocante à regulação e proteção vivencial pelo princípio do prazer. Entretanto, no Exposé de 1939, ele mantém a opção relatada ao amigo Gershom Scholem, em carta de 8 de abril de 1939, de poder finalizar o tópico "Baudelaire ou as ruas de Paris", das Passagens, com o poema "Os sete velhos" como epitáfio ao flâneur resignado à condição alucinatório-fantasmática que o assola e à sua degradação como mercadoria em meio à massa: "Finalmente o grande poema Les sept vieillards, a que nenhuma interpretação jamais se voltou, terá uma exegese surpreendente e, segundo espero, convincente" (SCHOLEM, 2003, 340). E mesmo considerando-se as mudanças realizadas expostas, a intenção de Benjamin em relação ao flâneur se volta de forma especial sobre esse poema de Baudelaire. ${ }^{7}$

Em "Os sete velhos", o flâneur aparece como o tipo do herói moderno de "nervos retesados" em fim de jornada, que ao sair para dar uma volta certa manhã, em meio aos choques e encontrões com a multidão, se vê replicado e ameaçado pela loucura na cidade alucinante:

Cidade a fervilhar, cheia de sonhos, onde O espectro, em pleno dia, agarra-se ao passante! Flui o mistério em cada esquina, cada fronde, Cada estreito canal do colosso possante.

(BAUDELAIRE, 2012, 318-323)

Essa fantasmagoria alucinante deflagra a caducidade da modernidade e expressa-se na imagem dos sete velhos como repetição, retorno do sempre igual:

\footnotetext{
7 "Os sete velhos" encontra-se na íntegra ao final deste artigo.

Mestre em Filosofia pela Unifesp. Residente em São Paulo - SP. Email: rosanabiondillo@gmail.com
} 
Sete vezes contei, minuto após minuto, / Este sinistro ancião que se multiplicava! // Teria eu visto o oitavo à luz do último instante, / Inexorável sósia, irônico e fatal /. Segundo Dolf Oehler: "N'Os sete velhos de Baudelaire é a própria realidade, com suas autocitações, que acossa o flâneur desprevenido e 0 reproduz degradadamente como tipo" (OEHLER, 2004, 245). Ao final, aterrorizado, o flâneur retorna para seu mundo privado como um fugitivo acossado: Furioso como um ébrio que vê dois em tudo, / Entrei, fechei a porta, trêmulo e perplexo, / (BAUDELAIRE, 2012, 318 - 323).

Olgária Matos diz que os velhos "se assemelham e se sucedem, em uma eterna repetição do horrível. O velho figura a repetição" (MATOS, 1989, 72). O olhar ébrio do flâneur já não é mais a virtude do que pratica a antissobriedade como antídoto a um mundo civilizado e mercantilizado: é agora o olhar do que vê a si mesmo como um tipo fantasmático reproduzido em série assim como as mercadorias. "A economia mercantil arma a fantasmagoria do igual" (ADORNO, 2012, 437), diz Benjamin a Adorno em carta de 23 de fevereiro de 1939. A imagem dos velhos se replicando em sósias do flâneur mostra o passado que perde sua força original, sua aura de tradição. O passado assim reproduzido evidencia a prevalência da vivência do choque, pois quando o flâneur perde a possibilidade de interagir e de simular outros papeis torna-se o ser atrofiado e desolado que só pode simular-se a si mesmo. Em sua análise, Benjamin propõe que Baudelaire indicou em duas estrofes, de forma velada como se fosse uma nota, que "o herói moderno não é herói - apenas representa o papel de herói" (BENJAMIN, 1994, 94). E completa: "como não possuía nenhuma convicção, estava sempre assumindo novos personagens" (BENJAMIN, 1994, 94). Entre eles, o mais expressivo: o de flâneur:

\footnotetext{
Certa manhã, quando na rua triste e alheia, As casas, a esgueirar-se no úmido vapor, Simulavam dois cais de um rio em plena cheia, E em que, cenário semelhante à alma do ator,

Uma névoa encardida enchia todo o espaço, Eu ia, qual herói de nervos retesados, A discutir com meu espírito ermo e lasso Por vielas onde ecoavam carroções pesados. (BAUDELAIRE, 2012, 318-323).
} 
Diferentemente das tempestades do herói clássico - que ao serem enfrentadas e combatidas agregavam, além do esforço e da dor, ensinamento e um novo modo de existência que não excluía, mas valorizava a tradição -, a tempestade que o flâneur não enfrenta, e, portanto, não luta, é apenas mais uma tempestade dentre outras. Evento entre eventos repetitivos, esse tempo de tempestades é a modernidade. Por isso, Benjamin reserva ao flâneur a imagem final de "Os sete velhos":

\footnotetext{
Minha razão debalde ao leme se agarrava;

A tempestade lhe rompia a quilha e as cordas,

E minha alma, ó naufrágio, dançava, dançava,

Sem mastros, sobre um mar fantástico e sem bordas!

(BAUDELAIRE, 2012, 318-323)
}

Se nos recordarmos de Ulisses - que pede para ser amarrado ao mastro de sua embarcação para não sucumbir ao (até então) fatal canto das sereias -, veremos que sua atitude demonstra que o herói racionaliza o desejo antes de se entregar ao destino. "Ulisses, herói do racionalismo mítico, só sai vitorioso da luta com as forças naturais porque sacrifica o que mais deseja, renuncia a seu sonho. Ascetismo e renúncia - de que Ulisses atado ao mastro é o emblema -, articula individualidade e divisão" (MATOS, 1989, 179). Mas Baudelaire cria um outro oceano com a visão alucinatória da multidão, sob cujo canto deixa-se sucumbir - o flâneur submerge na coletividade dos sem-sujeito. Como explica Benjamin: "O indivíduo que é assim representado na sua multiplicação, como sempre o mesmo, testemunha a angústia do cidadão de não mais poder, apesar da expressão de suas singularidades mais excêntricas, romper o círculo mágico do tipo" (BENJAMIN, 2009, $62)$.

O "círculo mágico do tipo" como replicantes e/ou réplicas propõe a reflexão de Benjamin de que na fantasmagoria do sempre-igual às pessoas homogeneizam-se e se re-produzem de modo semelhante às mercadorias. Nesse contexto, ele relaciona a teoria do eterno retorno à reprodutibilidade técnica: "A teoria do eterno retorno como um sonho sobre as monstruosas descobertas iminentes no terreno da técnica de reprodução" (BENJAMIN, 1994, 171). O flâneur, que antes jogava com os demais tipos sociais, transformando-se neles próprios, ao seu bel-prazer, sucumbe aos 
desmandos da realidade prática da vida e tem que disfarçar seus objetivos sob uma pretensa autonomia. O sujeito cede lugar ao tipo. Ao vislumbrar todas as fisionomias como uma única, o flâneur reconhece (-se como) o rosto da mercadoria.

Ainda sobre "Os sete velhos", há uma frase entre-parentêses no Exposé de 1939: "(A prova que pode ser apresentada de que essa poesia transcreve os sonhos de um viciado em haxixe não invalida em nada esta interpretação.) (BENJAMIN, 2009, 62). Essa observação de Benjamin encontra uma explicação na já mencionada carta a Adorno de 23/02/1939, quando ele apresenta o flâneur como tipo a ser desenvolvido no seu planejado (mas nunca finalizado) livro sobre Baudelaire: "Da perspectiva do meu trabalho sobre Baudelaire, a construção revisada apresenta-se assim: impor-se-á a definição da flânerie como um estado de embriaguez, e portanto sua comunicação com as experiências de Baudelaire com o uso de estupefacientes" (ADORNO, 2012, 437). Benjamin utiliza essa mesma argumentação em "O flâneur", no ensaio Paris do Segundo Império, para significar que a proliferação da mercadoria e seu encanto - que mantém subliminar seu efeito social - são produto do entorpecimento causado pela massa. Semelhante ao prazer que a droga propicia ao viciado, estar em meio à multidão pode trazer prazer momentâneo ao flâneur. Em anotação do "Arquivo M", Benjamin diz que a massa "é o mais novo alucinógeno do solitário", pois ela apaga "todos os rastros do indivíduo: é o mais novo refúgio do proscrito" (BENJAMIN, 2009, 490). Entretanto, nesse estágio terminal da flânerie, os nervos retesados do flâneur se assemelham ao de um abstinente que reconhece em todas as faces o rosto único da mercadoria. Para Benjamin, a alucinação artificial provocada por Baudelaire veio "em auxílio da alucinação histórica da igualdade que se aninhara na economia mercantil." (ADORNO, 2012, 436)

Lembramos brevemente Simmel que, em Questões fundamentais da sociologia: indivíduo e sociedade, discorre sobre o jogo social de faz-de-conta no qual todos são supostamente iguais ao mesmo tempo em que cada um presume-se como indivíduo único: "o faz de conta não é uma mentira, assim como não o são o jogo e a arte, com todos os seus desvios de realidade" (SIMMEL, 1973, 71). Assim, o faz-de-conta do flâneur também não é uma mentira, especialmente por ser inspirado nesse mesmo corpo coletivo representado pela multidão. O flâneur é expressão dessa multidão, uma vez que ao mesmo tempo em que tenta manter sua 
integridade física, individualidade e poder de decisão em meio a ela, celebrando-a, também a despreza na mesma proporção, pois sabe que é uma questão de tempo o vir a transformar-se em mais um passante a ser arrastado e desindividualizado. Essa postura do flâneur é antitética, pois ora o coloca como alguém em sintonia com seu tempo, ora em completa distonia, e é representativa de uma época que não encontra comodidade em nenhum sistema ou definição absoluta: a modernidade. $E$ se retornarmos brevemente ao já mencionado desfecho do poema em prosa "Perda de auréola", veremos que ele mostra como o fim da aura ${ }^{8}$ é análogo ao fim da subjetividade. Segundo Rouanet, o flâneur conhece essa condição "no momento em que o progresso da massificação o priva do direito à flânerie. Outrora observador neutro da massa, ele percebe, muito tarde, que foi arrastado por ela, transformandose em passante. E investe contra ela" (ROUANET, 1990, 68). Portanto, devemos considerar que, uma vez incorporado à massa, o indivíduo que caminha abrindo espaço em meio à multidão é exposto aos choques - age de forma reflexa e automática - e perde de vista as reminiscências dessa semelhança, não consegue mais identificá-la no momento presente. Transposto para os dizeres de Benjamin, podemos interpretar essa condição como perda da memória histórica e da capacidade crítica, ou seja, há o esvaziamento da experiência.

Nos termos benjaminianos de uma reflexão histórica, o flâneur também pode ser entendido como a caracterização do protetor do limiar que se forma entre o eterno, o sagrado, o longínquo da tradição, e o transitório, o profano, o imediato da modernização. Em outras palavras: o flâneur é aquele que "percebe" o distanciamento da transmissão da experiência tradicional (Erfahrung) - que também pode ser entendida nos termos de uma história anterior - no mundo moderno e o surgimento inexorável da vivência do choque (Chockerlebnis) - que torna o indivíduo alheio a qualquer reflexão, pois privação de experiência traduz-se em privação histórica. A originalidade do flâneur situar-se-ia exatamente nessa espécie de intermediação entre-mundos $e$, nesse contexto, ele se assemelha àquele que tem a chave para a abertura do portal: que levaria das imagens de sonho da arte e da

\footnotetext{
${ }^{8} \mathrm{O}$ conceito de aura em Benjamin não se limita à obra de arte, como explica Rouanet: "Relendo os textos de Benjamin, verificamos que sua concepção de aura é mais ampla que a que resulta do seu ensaio sobre a obra de arte. É uma categoria que se aplica, de forma muito genérica, ao mundo da natureza e ao mundo da cultura." (ROUANET, 1990, p. 68)
}

Mestre em Filosofia pela Unifesp. Residente em São Paulo - SP. Email: rosanabiondillo@gmail.com 
tradição ao das imagens do sonho de consumo e da exploração.

Quando Benjamin propõe "Os sete velhos" como final ao flâneur, a consumação dessa passagem estaria dada e poderia ser atestada nos modelos de reprodutibilidade técnica: "A teoria do eterno retorno como um sonho sobre as monstruosas descobertas iminentes no terreno da técnica de reprodução." (BENJAMIN, 1994, 171)

\title{
OS SETE VELHOS ${ }^{9}$
}

\author{
A Victor Hugo ${ }^{10}$
}

Cidade a fervilhar, cheia de sonhos, onde

O espectro, em pleno dia, agarra-se ao passante!

Flui o mistério em cada esquina, cada fronde,

Cada estreito canal do colosso possante.

Certa manhã, quando na rua triste e alheia,

As casas, a esgueirar-se no úmido vapor,

Simulavam dois cais de um rio em plena cheia,

E em que, cenário semelhante à alma do ator,

Uma névoa encardida enchia todo o espaço,

Eu ia, qual herói de nervos retesados,

A discutir com meu espírito ermo e lasso

Por vielas onde ecoavam carroções pesados.

Súbito um velho, cujos trapos pareciam

Reproduzir a cor do tempestuoso céu

$\mathrm{E}$ a cujo pobre aspecto esmolas choveriam,

Não fosse o mal que lhe brilhava no olho incréu,

Me apareceu. Dir-se-ia que, em fel banhada,

Sua pupila o ardor dos gelos aguçava,

E a barba, em longos pelos, qual aguda espada,

Análoga à de Judas, no ar se projetava.

Não era curvo, mas quebrado, e sua espinha

Compunha com a perna um claro ângulo reto,

Tanto mais que o bastão, que a seu perfil convinha,

\footnotetext{
${ }^{9}$ Baudelaire, C. "Os sete velhos". Tradução de Ivan Junqueira. In: As flores do mal, p. 318-323

${ }^{10}$ Baudelaire dedica três poemas da seção "Quadros parisienses", de As flores do mal, a Victor Hugo. Um dos motivos é terem em comum o tema da multidão e do oceano. A multidão em Hugo é objeto de contemplação: "Seu modelo é o oceano a quebrar-se contra as rochas, e o pensador que reflete sobre esse espetáculo é o verdadeiro investigador da multidão, na qual se perde como no rumor do mar", diz Benjamin. Segundo ele, Baudelaire disse que "o próprio oceano se cansou" de Hugo. Crítica mordaz ao contemplador da natureza, "Baudelaire não se sentia movido a se entregar ao espetáculo da natureza", completa Benjamin. (Benjamin, W. "Paris do Segundo Império". In: OE III, p. 56-57)
}

Mestre em Filosofia pela Unifesp. Residente em São Paulo - SP. Email: rosanabiondillo@gmail.com 
Lhe dava o ar retorcido e o ímpeto incorreto

De um quadrúpede enfermo ou judeu de três patas.

Ele ia, em meio à lama e à neve quase imerso,

Como quem mortos calca ao peso das sapatas,

De todo indiferente e hostil ao universo.

Outro o seguia: barba, dorso, olhos, molambos

- Enfim, tudo era igual, do mesmo inferno oriundo,

Neste gêmeo senil, e caminhavam ambos

Com mesmo passo não se sabe a que outro mundo.

A vítima eu seria de um conluio astuto?

Ou que perverso acaso ali me atormentava?

Sete vezes contei, minuto após minuto,

Este sinistro ancião que se multiplicava!

Aquele que se ri de tamanha inquietude, $E$ que jamais sentiu um frêmito fraterno, Cuide bem que, apesar de tal decrepitude,

Os sete hediondos monstros tinham o ar eterno!

Teria eu visto o oitavo à luz do último instante, Inexorável sósia, irônico e fatal,

Filho e pai de si mesmo ou Fênix repugnante?

- Mas as costas voltei ao cortejo infernal.

Furioso como um ébrio que vê dois em tudo, Entrei, fechei a porta, trêmulo e perplexo,

Transido e enfermo, o espírito confuso e mudo,

Fendido por mistérios e visões sem nexo!

Minha razão debalde ao leme se agarrava;

A tempestade Ihe rompia a quilha e as cordas,

E minha alma, ó naufrágio, dançava, dançava,

Sem mastros, sobre um mar fantástico e sem bordas!

\section{REFERÊNCIAS}

Mestre em Filosofia pela Unifesp. Residente em São Paulo - SP. Email: rosanabiondillo@gmail.com 
ADORNO, TW. Correspondência 1928 - 1940 Adorno - Benjamin. Tradução de José Marcos Mariani de Macedo, $1^{\underline{a}}$ ed. São Paulo: UNESP, 2012.

BAUDELAIRE, C. "Os sete velhos", "O relógio" in:_As flores do mal. Apresentação, tradução e notas de Ivan Junqueira, ed. especial. São Paulo: Saraiva, 2012.

BENJAMIN, W. "Paris do Segundo Império", "Sobre alguns temas em Baudelaire", "Parque Central", "O Flâneur", "Jogo e prostituição". Obras escolhidas III. Tradução de José Carlos Martins Barbosa e Hemerson Alves Baptista, $3^{\text {a }}$ ed. São Paulo: Brasiliense, 1994.

"Exposé de 1939", "Arquivo J", "Arquivo M" in: Passagens. Tradução de Irene Aron e Cleonice Paes Barreto Mourão, $1^{\underline{a}}$ ed. Belo Horizonte: UFMG, 2009.

MATOS, OCF. "Fetichismo e luxo: valor de exposição e imagens de desejo". in:_Benjaminianas: cultura capitalista e fetichismo contemporâneo, $1^{\underline{a}}$ ed. São Paulo: UNESP, 2010.

. "Aufklärung na metrópole: Paris e a Via Láctea" in:

Passagens. $1^{\mathrm{a}}$ ed. Belo Horizonte: UFMG, 2009.

"Uma história barroca", "A história iluminista" in: Os arcanos do inteiramente outro: a Escola de Frankfurt, a melancolia e a revolução. $2^{\mathrm{a}} \mathrm{ed}$. São Paulo: Brasiliense, 1989.

OEHLER, D. Terrenos vulcânicos. Tradução de Samuel Titan Jr, $1^{1}$ ed. São Paulo: Cosac \& Naify, 2004.

OTTE, G. "Dizem-me que sou louco" - as epistemologias poéticas de Baudelaire e Benjamin. Revista Alea vol. 9, oㅡ 2, jul-dez. Rio de Janeiro: UFRJ, 2007.

ROUANET, SP. Édipo e o anjo: itinerários freudianos em Walter Benjamin. $2^{\mathrm{a}}$ ed. Rio de Janeiro: Tempo Brasileiro, 1990.

SCHOLEM, G. Correspondência Walter Benjamin - Gershom Scholem. Tradução de Neusa Soliz, 1 ed. São Paulo: Perspectiva, 2003.

SIMMEL, G. Questões fundamentais da sociologia: indivíduo e sociedade. Tradução de Pedro Caldas, 1르 ed. Rio de Janeiro: Zahar, 1973. 